\title{
Treatment of Stable Keratoconus by Cataract Surgery with Toric IOL Implantation
}

\author{
Jaime Levy, Anry Pitchkhadze, Tova Lifshitz
}

\begin{abstract}
We present the case of a 73-year-old patient who underwent successful phacoemulsification and toric intraocular lens (IOL) implantation to correct high stable astigmatism due to keratoconus and cataract. P reoperative refraction was -3.25 $4.0 \times 98^{\circ}$. A toric IOL (Acrys of SN60T6) with a spherical power of 16.5 D and a cylinder power of 3.75 D at the IOL plane and $2.57 \mathrm{D}$ at the corneal plane was implanted and aligned at an axis of $0^{\circ}$. Uncorrected visual acuity improved from $6 / 60$ to $6 / 10$. Postoperative best corrected visual acuity was $6 / 6,6$ months after the operation. In conclusion, phacoemulsification with toric IOL implantation can be performed in eyes with keratoconus and cataract.
\end{abstract}

Keywords: Intraocular lens, Toric IOL, Keratoconus, Cataract surgery.

How to cite this article: Levy J, Pitchkhadze A, Lifshit T. Treatment of Stable Kerato conus by Cataract Surgery with Toric IO L Implantation. Int J Kerat Ect Cor Dis 2012;1(2):128-130.

\section{Source of support $\mathrm{Nil}$}

Conflict of interest: None

\section{INTRODUCTION}

Surgical correction of refractive errors in patients with keratoconus is still challenging. As the disease progresses, it is usually associated with significant astigmatism and often accompanied by myopia.

The use of special intraocular lens (IOL) in patients with nonprogressive keratoconus is a recent development in refractive surgery, with only a few published articles till date. ${ }^{1}$ There are just a few reports on the use of phakic IO Ls (angle-supported phakic IOLs, iris-fixated phakic IOL s and posterior chamber phakic IOLs), refractive lens exchange (with or without toric IOLs) and sequential surgery (intrastromal corneal ring and phakic IOLs) for cases of keratoconus and clear crystalline lens. When there is cataract associated with stable moderate to high astigmatism, phacoemul sification and implantation of a toric IOL can be performed.

We present a case of cataract surgery with toric IOL implantation in patient with keratoconus with stable topography for several years.

\section{CASE REPORT}

A 73-year-old man sought consultation due to decreased visual acuity in his left eye. Four years before he underw ent phacoemulsification and nontoric intraocular lens (IOL) implantation in the right eye. On presentation, uncorrected visual acuity (UCV A) was $6 / 60 \mathrm{OU}$. R efraction was -0.75 $-5.0 \times 65^{\circ}$ OD and $-3.25-4.0 \times 98^{\circ}$ OS. Nuclear sclerosis and posterior subcapsular cataract +2 was observed in the left eye. The posterior segments were unremarkable.

Corneal topography performed with Orbscan (Bausch and Lomb, Rochester, NY ) showed central thinning of 457 microns and positive islands of elevation typical for keratoconus in the right eye (Fig. 1). In the left eye a less pronounced inferior cone was observed (Fig. 2), without any area of significant thinning near the limbus typical for pellucid marginal degeneration. ${ }^{2}$ Keratometry (K)-values on EyeSys (EyeSys L aboratories, Houston, TX) for the steep and flat axis were $57.49 \mathrm{D}$ at $138^{\circ}$ and $52.57 \mathrm{D}$ at $48^{\circ} \mathrm{OD}$ and were $47.73 \mathrm{D}$ at $0^{\circ}$ and $45.48 \mathrm{D}$ at $90^{\circ} \mathrm{OS}$ (Fig. 3). Corneal topography was stable for several years.

Due to the postoperative high residual astigmatism in the right eye we decided to perform phacoemulsification and implant a toric IOL in the left eye. A web-based toric IOL calculator program was used to determine the optimal cylinder power and alignment axis of the IOL (http: // www.acrysoftoriccal culator.com).

A standard phacoemulsification was performed with a $3.2 \mathrm{~mm}$ limbal incision at $90^{\circ}$. A hydrophobic acrylic toric IOL (A crysof SN 60T6, A Icon, L td, Fort W orth, TX) with a spherical power of $16.5 \mathrm{D}$ and a cylinder power of $3.75 \mathrm{D}$ at the $10 \mathrm{~L}$ plane and $2.57 \mathrm{D}$ at the corneal plane was implanted and aligned at an axis of $0^{\circ}$. Three weeks after surgery, the UCVA was $6 / 12$ and the best spectaclecorrected visual acuity (BSCV A) was 6/7.5 and 3 months after surgery UCV A was $6 / 10$ and BSCV A was $6 / 6$ with a refraction of $0.75-1.5 \times 125^{\circ}$. Six months after the procedure, patient's satisfaction is high and refraction remains stable.

\section{DISCUSSION}

Eyes with keratoconus eye suitable for IOL implantation should have a central cl ear cornea, mild astigmatism, stable refraction and good BSCV A. ${ }^{1}$ There are just a few reports on the use of phakic IOLs, refractive lens exchange and sequential surgery suggesting good predictability, efficacy and safety.

Toric IOLs can be implanted in the bag in cases of keratoconus and clear crystalline lens or cataract. Navas 


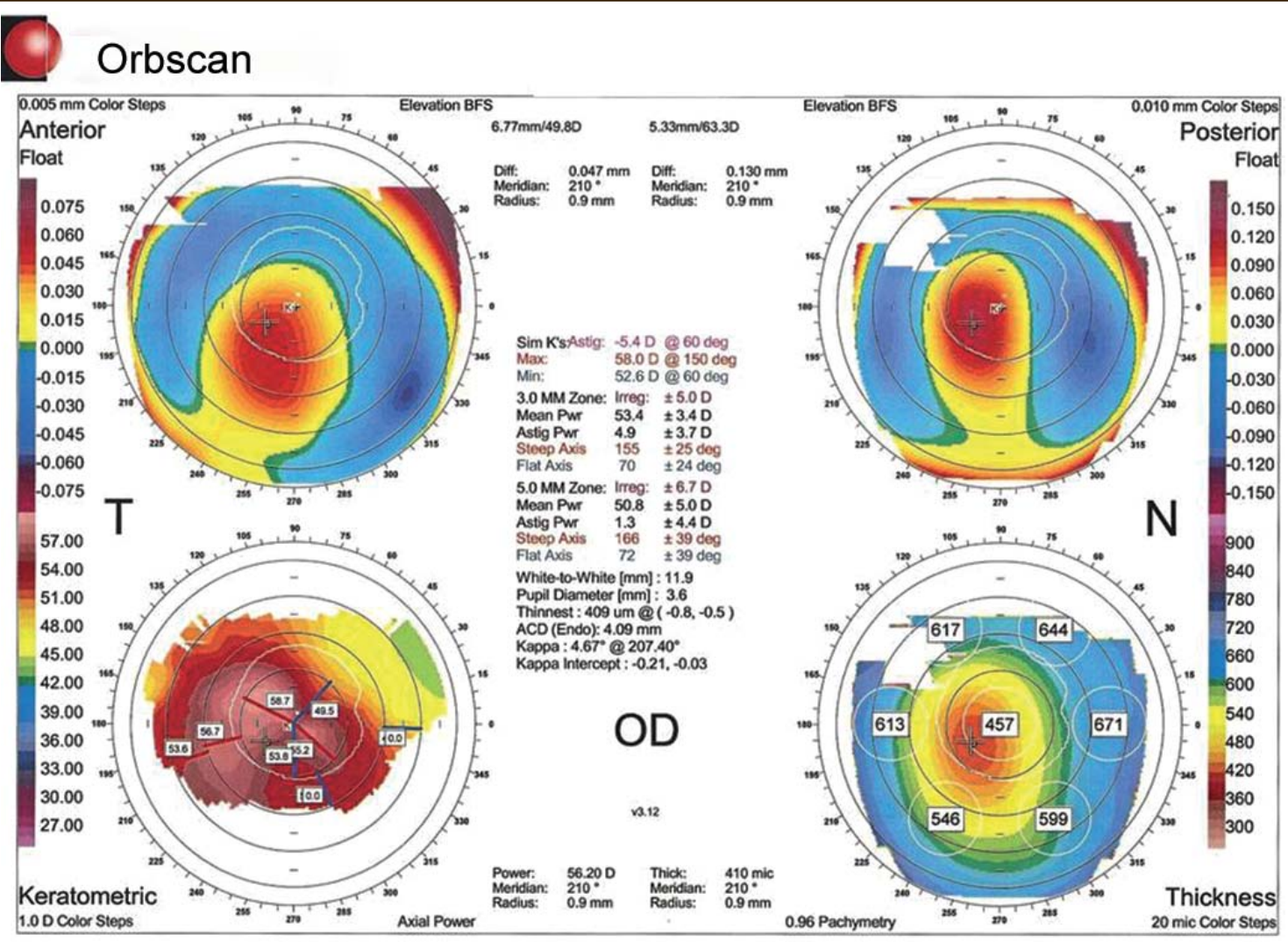

Fig. 1: Corneal topography of the right eye (Orbscan, Bausch and Lomb, Rochester, NY)

\section{Orbscan}
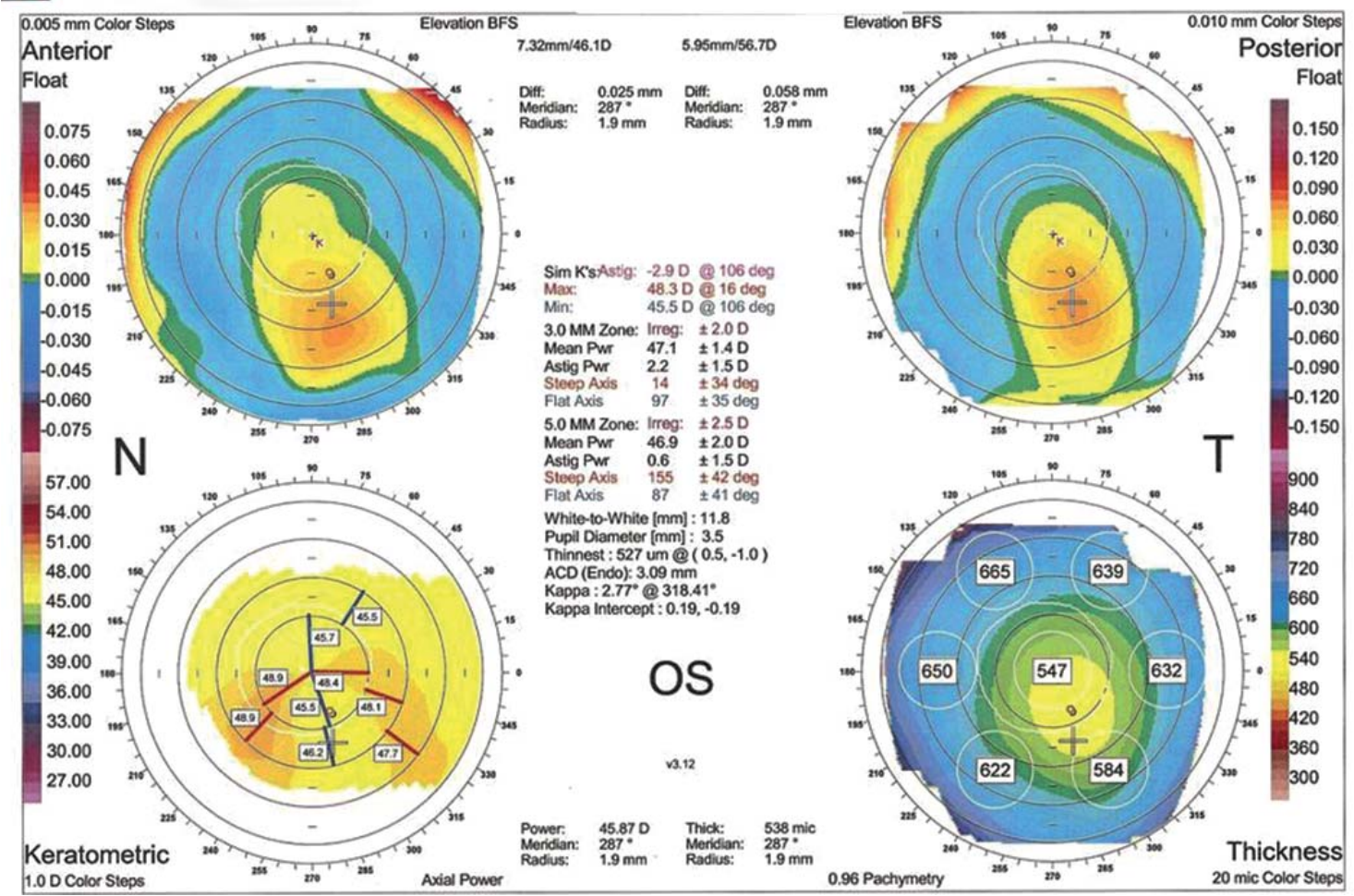

Fig. 2: Preoperative corneal topography of the left eye (Orbscan, Bausch and Lomb, Rochester, NY)

and Suárez ${ }^{3}$ were the first to report the use of a toric IOL (A crySof toric SN 60TT IOL, A Icon, Inc.) for forme fruste keratoconus without cataract. Preoperative refraction was $-6.50-3.00 \times 135^{\circ}$ and $-5.00-3.00 \times 85^{\circ}$. One year postoperatively, the U CVA was $20 / 25$ in both cases, with a refraction of $-0.25-0.50 \times 140^{\circ}$ and $0.25-0.50 \times 60^{\circ}$ respectively. No progression and no IOL rotation were observed. 


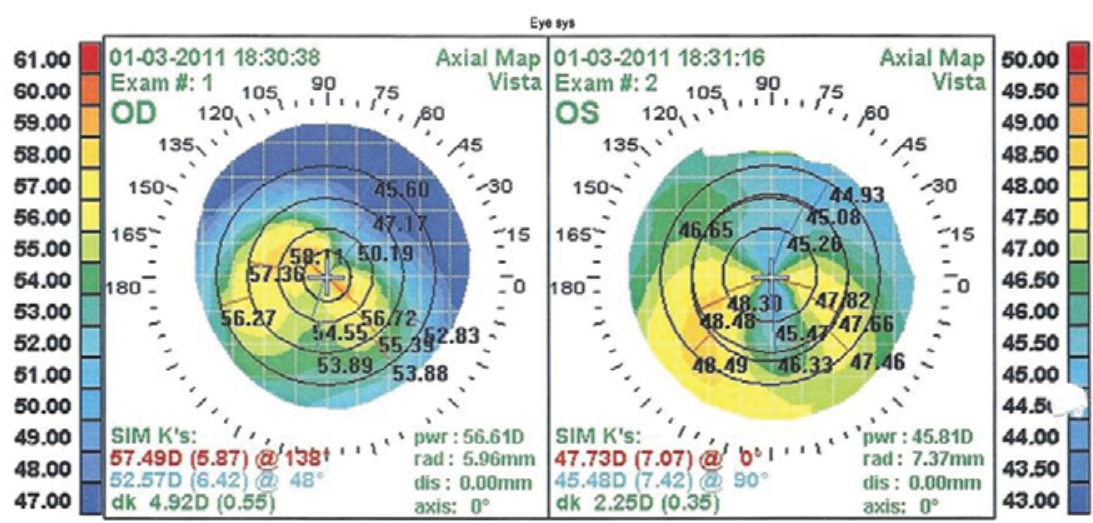

Fig. 3: Keratometry of both eyes (EyeSys, EyeSys Laboratories, Houston, TX)

J aimes et $\mathrm{al}^{4}$ retrospectively reviewed 19 eyes with keratoconus treated with refractive lens exchange and inthe bag toric IOL implantation (models T3 to T9, A cryS of SN60TT; Alcon Laboratories Inc). All cases had topographic and/or refractive stability for at least 1 year prior to undergoing $10 \mathrm{~L}$ implantation. M ean preoperative sphere was $-5.25 \pm 6.40$ diopters (D), and mean postoperative sphere was $0.22 \pm 1.01 \mathrm{D}$. M ean preoperative cylinder was $3.95 \pm 1.30 \mathrm{D}$, which decreased to $1.36 \pm 1.17$ D postoperatively. Preoperative mean UCVA was 20/447 and postoperative mean UCVA was 20/39.

Finally $\mathrm{V}$ isser et $\mathrm{al}{ }^{5}$ reported on three eyes of keratoconus and cataract, phacoemulsification with a toric IOL (cylinder power: $3.0-6.0 \mathrm{D}$ ). UCV A increased from $20 / 400$ to $20 / 130-20 / 30$. The ref ractive cylinder decreased by 70 to $75 \%$ postoperatively. No IOL misalignment or other complications occurred.

Good results have been also achieved with IOL implantation in cases of pellucid marginal degeneration (PM D) ${ }^{6-8}$ It is crucial that the refraction will be stable for at least 6 months before the procedure. ${ }^{6}$ It has been suggested by some authors that the results in PM D may be better than in keratoconus because the astigmatism at the center of the cornea is more regular in PM D, although there are no comparative studies till date.

In our case a significant improvement in UCVA was observed from $6 / 60$ preoperatively to $6 / 10,3$ months after the procedure compared with the fellow eye in which significant residual high astigmatism remained after the implantation of a standard nontoric IOL.

\section{CONCLUSION}

Toric IO L implantation can be used to correct high stable astigmatism associated to keratoconus in eyes with cataract.

\section{REFERENCES}

1. L evy J, Lifshitz T. Intraocular lenses in keratoconus. A del Barbara, (Ed): The textbook of keratoconus. J aypee B rothers M edical Publishers, Chapter 20, 2011;209-16.

2. Belin M W, A sota IM , A mbrosio R J r, K hachikian SS. What's in a name: Keratoconus, pellucid marginal degeneration, and related thinning disorders. A m J O phthalmol 2011;152:157-62.

3. N avas A, Suárez R. O ne-year follow-up of toric intraocular lens implantation in forme fruste keratoconus. J C ataract R efract Surg 2009;35:2024-27.

4. Jaimes M, Xacur-García F, Alvarez-M elloni D, GraueHernández EO, Ramirez-Luquín T, Navas A. R efractive lens exchange with toric intraocular lenses in keratoconus. J R efract Surg 2011;27:658-64.

5. V isser N, Gast ST, Bauer NJ , N uijts R M . Cataract surgery with toric intraocular lens implantation in keratoconus: A case report. Cornea 2011;30:720-23.

6. Luck J. Customized ultra-high-power toric intraocular lens implantation for pellucid marginal degeneration and cataract. J Cataract R efract Surg 2010;36:1235-38.

7. K amiya K, Shimizu K, Hikita F, K omatsu M . Posterior chamber toric phakic intraocular lens implantation for high myopic astigmatism in eyes with pellucid marginal degeneration. J Cataract R efract Surg 2010;36:164-66.

8. de V ries NE, Tahzib NG, W ebers CA, Hendrikse F, N uijts RM . $U$ se of $V$ erisyse/A rtisan phakic intraocular lens for the reduction of myopia in a patient with pellucid marginal degeneration. Cornea 2008;27:241-45.

\section{ABOUT THE AUTHORS}

\section{Jaime Levy (Corresponding Author)}

Ophthalmologist, D epartment of O phthalmology, Soroka University M edical Center, B eer-sheva, Israel, e-mail: Ijaime@ bgu.ac.il

\section{Anry Pitchkhadze}

Ophthalmologist, D epartment of O phthalmology, Soroka University $M$ edical Center, B eer-sheva, Israel

\section{Tova Lifshitz}

Chair, Department of Ophthalmology, Soroka University M edical Center, B eer-sheva, Israel 